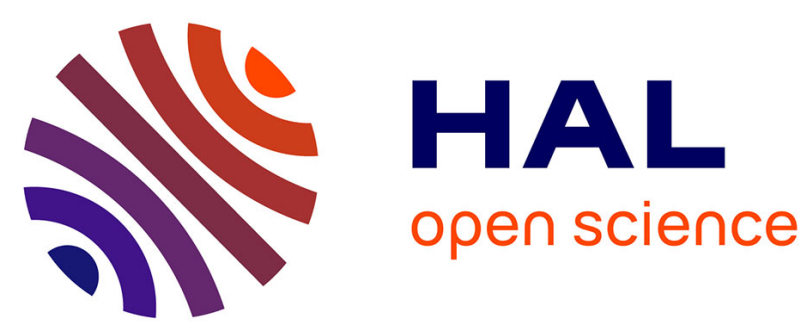

\title{
130-MHz Optomechanical Vibrating Sensor: Towards High Bandwidth / Ultrasensitive Measurements
}

Lucien Schwab, Pierre-Etienne Allain, Louise Banniard, Nicolas Mauran, Denis Lagrange, Alexandre Fafin, Marc Gély, Maxime Hermouet, Guillaume Jourdan, Sebastien Hentz, et al.

\section{To cite this version:}

Lucien Schwab, Pierre-Etienne Allain, Louise Banniard, Nicolas Mauran, Denis Lagrange, et al.. 130$\mathrm{MHz}$ Optomechanical Vibrating Sensor: Towards High Bandwidth / Ultrasensitive Measurements. IEEE 32nd International Conference on Micro Electro Mechanical Systems (MEMS 2019), Jan 2019, Seoul, South Korea. pp.819-822, 10.1109/MEMSYS.2019.8870718 . hal-02371188

\author{
HAL Id: hal-02371188 \\ https://hal.laas.fr/hal-02371188
}

Submitted on 1 Dec 2021

HAL is a multi-disciplinary open access archive for the deposit and dissemination of scientific research documents, whether they are published or not. The documents may come from teaching and research institutions in France or abroad, or from public or private research centers.
L'archive ouverte pluridisciplinaire HAL, est destinée au dépôt et à la diffusion de documents scientifiques de niveau recherche, publiés ou non, émanant des établissements d'enseignement et de recherche français ou étrangers, des laboratoires publics ou privés. 


\section{0-MHz OPTOMECHANICAL VIBRATING SENSOR: TOWARDS HIGH BANDWIDTH / ULTRASENSITIVE MEASUREMENTS}

Lucien Schwab ${ }^{1}$, Pierre-Etienne Allain ${ }^{2}$, Louise Banniard ${ }^{3}$, Nicolas Mauran ${ }^{1}$, Denis Lagrange ${ }^{1}$, Alexandre Fafin ${ }^{3}$, Marc Gely ${ }^{3}$, Maxime Hermouet ${ }^{3}$, Guillaume Jourdan ${ }^{3}$, Sébastien Hentz, Ivan Favero ${ }^{2}$ and Bernard Legrand ${ }^{1}$

${ }^{1}$ CNRS, University of Toulouse, LAAS-CNRS, Toulouse, FRANCE

${ }^{2}$ Matériaux et Phénomènes Quantiques, Univ. Paris Diderot, CNRS UMR 7162, Paris, FRANCE ${ }^{3}$ Univ. Grenoble Alpes, CEA, LETI, 38000 Grenoble, FRANCE

\begin{abstract}
We show all-optical operation of a VLSI optomechanical micro-resonator designed for high resolution sensing applications. Mechanical resonance frequency is above $100 \mathrm{MHz}$ with Q-factor of 1000 in air, yielding measurement bandwidth above $100 \mathrm{kHz}$. We demonstrate low thermomechanical noise floor resolved with exquisite motion detection limit down to $4.10^{-16} \mathrm{~m} . \mathrm{Hz}^{-0.5}$. This performance, enabled by optomechanical transduction, paves the way for very high-speed and ultra-sensitive sensing applications.
\end{abstract}

\section{INTRODUCTION}

MEMS technologies and transductions have played a key role in the sensing field, for example by the development and fabrication of force sensors vibrating in the $\mathrm{kHz}-\mathrm{MHz}$ range [1,2]. As fabrication technological processes developed, sensors' dimensions were shrunk in NEMS, looking for a twofold advantage: higher sensitivity and higher bandwidth, enabled by scaling laws and frequency increase. However, displacement transduction schemes usually at play in MEMS, like the capacitive one, are generally not applicable to NEMS [3]. Thanks to different integrated transduction means, NEMS have however proven their effectiveness in many sensing fields providing for example, $43 \mathrm{MHz}$ cantilevers, piezoresistive nanowire gauges detected, for gas chromatography [4] and chemisorptive mass sensing with piezoresistive metal film detection of a $127 \mathrm{MHz}$ cantilever resonance [5].

To reach mechanical frequencies greater than the $\mathrm{MHz}$, another path followed is to exploit bulk or inplane modes instead of shrinking dimensions of cantilever beams resonating on flexural modes. This idea was applied for ring-shaped force sensors [6], achieving a $13 \mathrm{MHz}$ breathing mode frequency record in AFM probes with a novel capacitive detection scheme based on microwave reflectometry, allowing high-bandwidth measurements without compromises on the femtometer resolution.

To go further, one needs to increase the frequency even higher and seek for higher displacement sensitivity to keep a reasonable signal-to-noise ratio due to the decrease in amplitude when the mechanical frequency raises. Consequently, force sensors vibrating above $100 \mathrm{MHz}$ with picometer amplitudes imply once more drastic constraints on usual integrated electromechanical transduction schemes and locks are met in terms of measurement resolution [7], calling for a change in transduction mean.
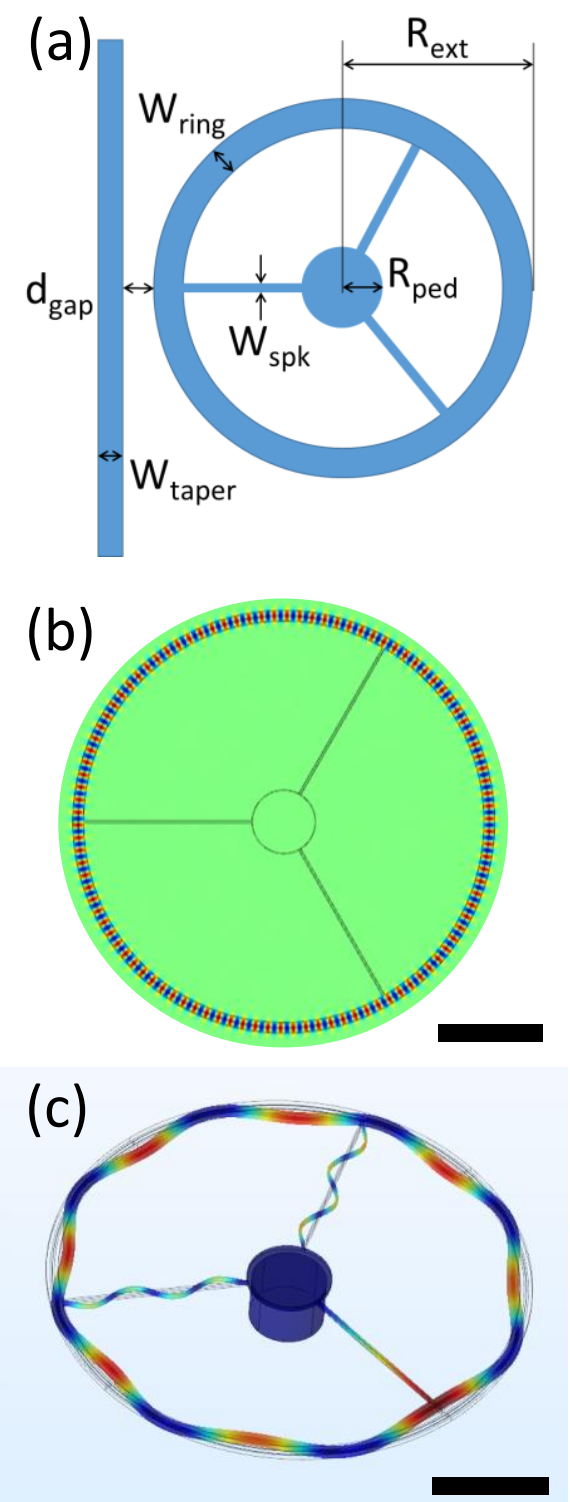

Figure 1: (a) Device schematic highlighting the main dimensions of the tested sensor structure: $R_{\text {ext }}=10 \mu \mathrm{m}, R_{\text {ped }}=1.5 \mu \mathrm{m}, W_{\text {ring }}=500 \mathrm{~nm}, W_{\text {spk }}=$ $100 \mathrm{~nm}, W_{\text {taper }}=475 \mathrm{~nm}$ and $d_{\text {gap }}=300 \mathrm{~nm}$.

(b) Optical and (c) mechanical finite element modeling of the optomechanical sensor, consisting in a $20 \mu \mathrm{m}$ diameter silicon ring with 3 spokes

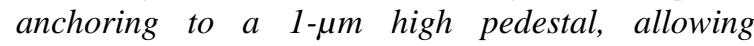
mechanical motion. Electrical field amplitude and displacement resonance mode are respectively simulated. The optical and mechanical resonance wavelength and frequency are $\lambda=1.55 \mu \mathrm{m}$ and $f_{m}$ simulated $=134 \mathrm{MHz}$ respectively, scale bars: $5 \mu \mathrm{m}$. 
Concurrently, quantum experiments at mesoscale [8] pushed understanding and engineering capability of optomechanical transduction at play in whispering gallery mode (WGM) resonators. This growing interest lead to III-V material integrated sensors resonating above $100 \mathrm{MHz}$ with ultimate motion sensitivity down to $10^{-17} \mathrm{~m} . \mathrm{Hz}^{-0.5}[9]$. This technology was successfully applied to scanning probe technique [10] and transferred to silicon photonics and very large scale integration facility in the last years [11].

To address the need in resonating devices for physical sensing applications with unprecedented performances, namely higher frequency, bandwidth and sensitivity, we present the design, fabrication and first characterization of a fully integrated, optically sensed, resonating sensor based on cavity optomechanics fabricated using a VLSI silicon photonics platform. The $130 \mathrm{MHz}$-frequency resonator presented hereafter offers an exquisite detection limit of $4.10^{-16} \mathrm{~m} . \mathrm{Hz}^{-0.5}$ and a measurement bandwidth of $130 \mathrm{kHz}$, being ruled by the relaxation time.

\section{OPTOMECHANICAL SENSOR DESIGN}

The sensor consists in a $20 \mu \mathrm{m}$ diameter ring WGM optical cavity (Fig. 1a) standing in air on a 1- $\mu$ m-high pedestal with three anchoring spokes. An optical waveguide evanescently couples the $1.55 \mu \mathrm{m}$ laser light in and out the optical mode. The ring is designed from the

(a)
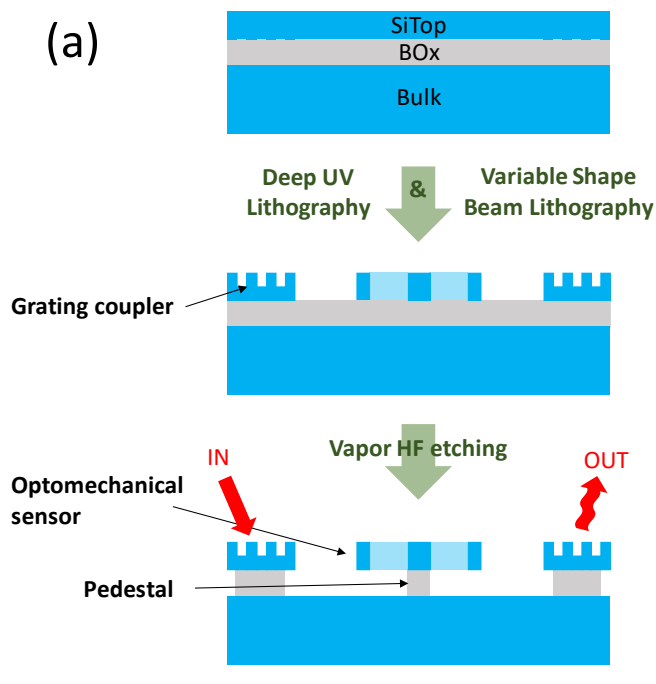

(b)

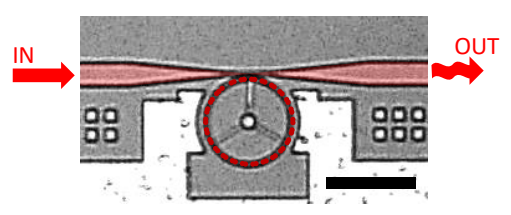

Figure 2: (a) Main fabrication steps of the optomechanical sensor. The silicon layer SiTop in which the optomechanical sensor is patterned is $220 \mathrm{~nm}$ thick. The 1- $\mu \mathrm{m}$ thick buried oxide layer (Box) is then etched to let only a $3 \mu \mathrm{m}$ diameter pedestal for the sensor to stand on. (b) Colorized SEM image of the resulting optomechanical sensor featuring the coupling waveguide (plain red) and the optical cavity (dotted red). Scale bar: $20 \mu \mathrm{m}$. mechanical point of view to reach a $134 \mathrm{MHz}$ first order breathing mode that is simulated by finite element method (FEM) with a $g_{\text {om }}=7.810^{18} \mathrm{~Hz} / \mathrm{m}$ optomechanical factor. For applications in mass or force sensing, one needs to seek the location of the lowest effective mass or stiffness of the resonator. This is reached at a location of the resonance mode shape where the vibration amplitude is maximal (See Fig. 1c). For the device presented in this study, effective mass and stiffness are calculated by FEM to be $6.10^{-14} \mathrm{~kg}$ and $40000 \mathrm{~N} / \mathrm{m}$ respectively at a point of maximum of vibration.

Principle of operation of the optomechanical device is as follows. Mechanical breathing motion of the resonator during its vibration modulates the cavity optical length and thus its optical transmission. This benefits from sensitivity enhancement by the WGM optical quality factor $Q_{\text {opt }}=60000$. Gap distance between the coupling waveguide and the ring cavity and dimensions of the sensor were designed to maximize the contrast times optical quality factor product.

\section{FABRICATION}

The ring sensor is fabricated using VLSI silicon photonics SOI technology on a $200 \mathrm{~mm}$ wafer. First, a deep UV lithography step defines the grating couplers enabling top-injection and collection of laser light, respectively in and out of the chip. Then a variable shape beam lithography step defines the ring sensor structure. The patterned silicon structural layer (SiTop) is $220 \mathrm{~nm}$ thick on top of a 1- $\mu$ m thick buried oxide layer (BOx). The BOx layer is then critically timed-etched with vapor$\mathrm{HF}$ in order to form the pedestal on which the sensor is finally standing on. Main steps of the fabrication process and SEM picture of the resulting sensor are depicted in figure 2 .

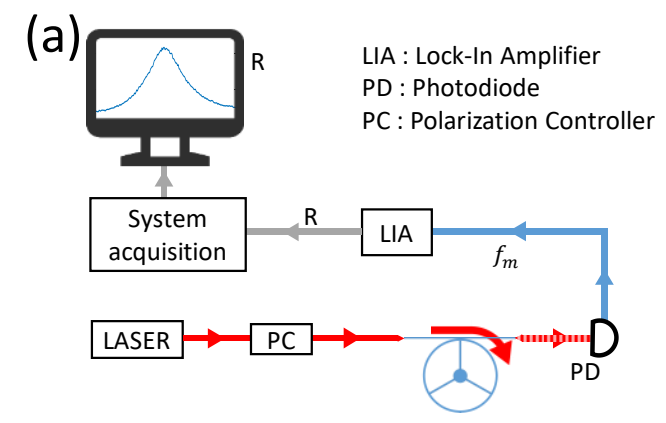

(b)

\begin{tabular}{l|l}
\multicolumn{1}{c|}{ Function } & \multicolumn{1}{|c}{ Piece of material } \\
\hline Tunable LASER & Photonetics OSICS-ECL-1560-P6 \\
EOM & Thorlabs LN58S-FC \\
LIA & Zurich Instruments HF2LI \\
PD & Thorlabs DET01CFC
\end{tabular}

Figure 3: (a) Set-up used for experimental characterisations. Laser light evanescently couples to the device. Laser light exiting the sensor then carries the mechanical resonance motion. Sensing signal from the photodiode is processed by a lock-in amplifier acting as a spectrum analyzer. (b) Table of the main equipment used to acquire the measurement data displayed in this manuscript. 


\section{CHARACTERIZATION SET-UP}

Experimental characterizations are performed in air. A lock-in amplifier (LIA) allows frequency characterization of the sensor (Fig. 3). Laser light is topinjected with fibers in the silicon chip via grating couplers optimized for optical C-band operation. Polarization controllers ensure that light is injected in the ring matching coupling polarization. A $1500-1600 \mathrm{~nm}$ tunable laser allows to match optical modes of the ring cavity. Transmitted light, modulated by the resonator motion, is then collected by a $1.2 \mathrm{GHz}$ bandwidth photodiode. Because of thermo-optic effect, the laser wavelength is blue-detuned which could enhance resonance through optical back-action. Injected power was thus limited to $1 \mathrm{~mW}$ to prevent from this enhancement effect.

\section{RESULTS \& DISCUSSION}

Thermomechanical (Brownian) motion is resolved (Fig. 4), at $f_{m}=130.6 \mathrm{MHz}$ with a $3 \%$ difference with simulated breathing mode frequency, and $Q_{m}=1000$ in air. Air fluid dissipation hinders the intrinsic mechanical Q-factor that would be obtained in vacuum, expected to be $Q_{m \_v a c}=10000$ from numerical calculations. Brownian motion detection, routinely enabled by optomechanical transduction, is calibrated in two different ways. First, we use the equipartition theorem (See "Thermomechanical noise displacement" formula in Table 1) which yields a $7.10^{-16} \mathrm{~m} \cdot \mathrm{Hz}^{-0.5}$ displacement noise density at the mechanical resonance frequency. The measured value, calibrated from the parameters of the detection chain, gives a $12.10^{-16} \mathrm{~m} . \mathrm{Hz}^{-0.5}$ value. The small discrepancy is within the uncertainty of the detection chain parameters and gains. Using this latter calibration value, the limit of detection of the measurement set-up is estimated to be below $4 \cdot 10^{-16} \mathrm{~m} \cdot \mathrm{Hz}^{-0.5}$. By assuming an operation of the device in driven mode, a $63 \mathrm{~dB}$ SNR could be attained for a vibration amplitude of $1 \mathrm{pm}$, which is better than for other devices in the same frequency range as presented in Table 1. Thanks to its high mechanical resonance frequency, our optomechanical sensor reaches a bandwidth of $130 \mathrm{kHz}$ in air, ruled by the $f / Q_{m}$ ratio, still competitive with regards to other resonating sensors (Table 1 ).

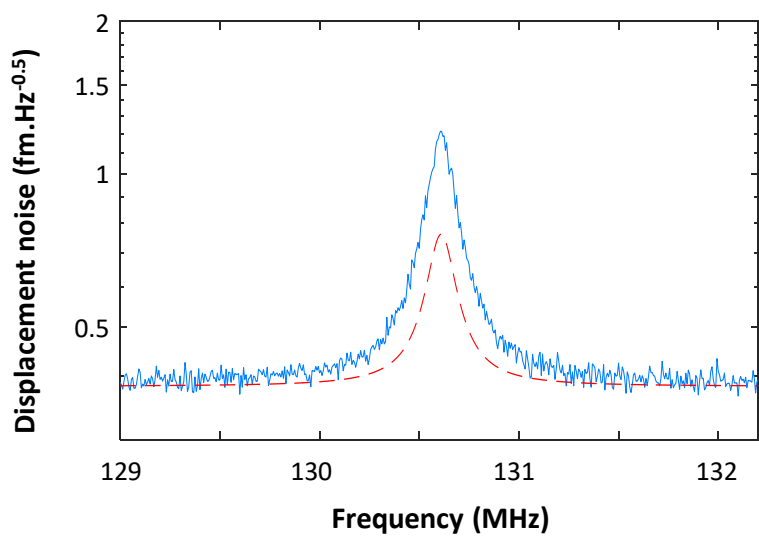

Figure 4: (Blue) Brownian motion of the optomechanical resonator measured at $1-\mathrm{Hz}$ bandwidth. Resonance frequency is $f_{m}=130.6 \mathrm{MHz}$. The sensor's quality factor attains $Q_{m}=1000$ in air. The signal is calibrated via detection chain. (Red) Brownian motion theory given by the equipartition theorem with same noise floor. The 1.7 factor between theoretical and measured noise amplitude is within detection parameters uncertainty.

\section{CONCLUSION}

An optomechanical ring resonator, mechanical frequency being up to $130 \mathrm{MHz}$, is fabricated using VLSI silicon photonics technology and characterized with an exquisite $4 \cdot 10^{-16} \mathrm{~m} \cdot \mathrm{Hz}^{-0.5}$ detection limit, allowing clear resolution of the thermomechanical motion. Those exquisite performances put high-bandwidth sensing along with femtometer displacement resolution within grasp.

\section{ACKNOWLEDGEMENTS}

This work was supported by the French National Research Agency (ANR) under the research project OLYMPIA, grant ANR-14-CE26-0019 and by the Délégation Générale de l'Armement (DGA).

\begin{tabular}{|c|c|c|c|c|c|c|c|}
\hline & & & & Ring sensor [6] & $\begin{array}{c}\text { Simple-clamped } \\
\text { beam [12] }\end{array}$ & $\begin{array}{c}\text { Simple-clamped } \\
\text { beam [5] }\end{array}$ & Present work \\
\hline Transduction & & & & Capacitive & $\begin{array}{c}\text { Piezoresistive } \\
\text { NW }\end{array}$ & $\begin{array}{l}\text { Piezoresistive } \\
\text { film }\end{array}$ & $\begin{array}{c}\text { Opto- } \\
\text { mechanical }\end{array}$ \\
\hline VLSI & & & & No & Yes & No & Yes \\
\hline Frequency & $f$ & MHz & & 13 & 43 & 127 & 130 \\
\hline Quality factor & $Q$ & in air & & 760 & 165 & 400 & 1000 \\
\hline Stiffness & $\boldsymbol{k}$ & $\mathbf{N} / \mathbf{m}$ & & 200000 & 27000 & 32 & 40000 \\
\hline $\begin{array}{l}\text { Thermomechanical noise } \\
\text { displacement }\end{array}$ & $A_{t h}$ & $\mathrm{fm} / \sqrt{\mathrm{Hz}}$ & $\sqrt{\frac{2 k_{B} T Q}{\pi f k}}$ & 0,9 & 0,6 & 16 & 0.7 \\
\hline Limit of detection & $L O D$ & $\mathrm{fm} / \sqrt{\mathrm{Hz}}$ & & 1,5 & 3 & 39 & 0.4 \\
\hline Bandwidth & $B W$ & $\mathbf{k H z}$ & $f / Q$ & 16 & 260 & 317 & 130 \\
\hline
\end{tabular}

Table 1: Main characteristics of various MNEMS resonating sensors 


\section{REFERENCES}

[1] J. Brugger, R. A. Buser and N. F. de Rooij. Micromachined atomic force microprobe with integrated capacitive read-out. Journal of Micromechanics and Microengineering, 2, 218-220, 1992

[2] E. Algre, Z. Xiong, M. Faucher, B. Walter, L. Buchaillot and B. Legrand. MEMS Ring Resonators for Laserless AFM With Sub-nanoNewton Force Resolution. Journal of Microelectromechanical Systems, 21, 385-397, 2012

[3] M. L. Roukes. Nanoelectromechanical systems face the future. Physics World, 14, 25-31, 2001

[4] J. Arcamone, A. Niel, V. Gouttenoire, M. Petitjean, N. David, R. Barattin, M. Matheron, F. Ricoul, T. Bordy, H. Blanc, J. Ruellan, D. Mercier, N. Pereira-Rodrigues, G. Costa, V. Agache, S. Hentz, JC Gabriel, F. Baleras, C. Marcoux, T. Ernst, L. Duraffourg, E. Colinet, E.B. Myers, M.L. Roukes, P. Andreucci, E. Ollier, and P. Puget. VLSI silicon multi-gas analyzer coupling gas chromatography and NEMS detectors. 2011 International Electron Devices Meeting, 29.3.1-29.3.4, 2011

[5] Mo Li, H.X. Tang and M.L. Roukes. Ultra-sensitive NEMS-based cantilevers for sensing, scanned probe and very high-frequency applications. Nature Nanotechnology, 2, 2, 114-120, 2007

[6] Bernard Legrand, Jean-Paul Salvetat, Benjamin Walterc, Marc Faucher, Didier Théron, Jean-Pierre Aimé. Multi-MHz micro-electro-mechanical sensors for atomic force microscopy. Ultramicroscopy, 175, 46-57, 2017

[7] K.L. Ekinci. Electromechanical Transducers at the Nanoscale: Actuation and Sensing of Motion in Nanoelectromechanical Systems (NEMS). Small, 1, 786-797, 2005
[8] R. Rivière, S. Deléglise, S. Weis, E. Gavartin, O. Arcizet, A. Schliesser, and T. J. Kippenberg. Optomechanical sideband cooling of a micromechanical oscillator close to the quantum ground state. Physical Review A, 83, 063835, 2011

[9] Lu Ding, Christophe Baker, Pascale Senellart, Aristide Lemaitre, Sara Ducci, Giuseppe Leo, and Ivan Favero. High Frequency GaAs Nano-Optomechanical Disk Resonator. Physical Review Letters, 105, 263903, 2010

[10] Y. Yuxiang Liu, Houxun Miao, Vladimir Aksyuk, and Kartik Srinivasan. Wide cantilever stiffness range cavity optomechanical sensors for atomic force microscopy. Optics Express, 20, 18268, 2012

[11] Maxime Hermouet, Marc Sansa, Louise Banniard, Alexandre Fafin, Marc Gely, Pierre-Etienne Allain, Eduardo G. Santos, Ivan Favero, Thomas Alava, Guillaume Jourdan and Sébastien Hentz. Ultra sensitive optomechanical microdisk resonators with very large scale integration process. IEEE Micro Electro Mechanical Systems (MEMS), pp. 844-845, 2018

[12] I. Ouerghi, M. Sansa, W. Ludurczak, L. Duraffourg, K. Benedetto, P. Besombes, T. Moffitt, B. Adams, D. Larmagnac, P. Gergaud, C. Poulain, A. I. Vidaña, C. Ladner, J. M. Fabbri, D. Muyard, G. Rodriguez, G. Rabille, O. Pollet, P. Brianceau, S. Kerdiles, S. Hentz and T. Ernst. Polysilicon Nanowire NEMS fabricated at low temperature for above IC NEMS mass sensing applications. 2015 IEEE International Electron Devices Meeting (IEDM), 18.3.1-18.3.4, 2015

\section{CONTACT}

Lucien Schwab, 1schwab@laas.fr 